\title{
Photophysical Investigation of A Benzimidazole Derivative and Its Applications In Selective Detection of Fe3+, Thermosensing and Logic gates.
}

\section{Aishwarya Nadgir}

Karnatak University Dharwad Department of Physics

Ashok H Sidarai ( $\sim$ ashok_sidarai@rediffmail.com )

Department of Physics, Karnatak University Dharwad, Karnataka, India. https://orcid.org/0000-00015673-4159

\section{Research Article}

Keywords: Expired medicine, Fe3+ sensor, Thermal sensor, NOR-gate, Fluorescent Ink

Posted Date: May 10th, 2021

DOI: https://doi.org/10.21203/rs.3.rs-449549/v1

License: (c) (1) This work is licensed under a Creative Commons Attribution 4.0 International License.

Read Full License

Version of Record: A version of this preprint was published at Journal of Fluorescence on July 21st, 2021. See the published version at https://doi.org/10.1007/s10895-021-02790-5. 
Photophysical investigation of a Benzimidazole derivative and its applications in Selective detection of $\mathrm{Fe}^{3+}$, Thermosensing and Logic gates.

\author{
Aishwarya Nadgir ${ }^{\mathrm{a}}$ and Ashok H. Sidarai ${ }^{\text {** }}$ \\ ${ }^{a}$ Department of Studies in Physics, karnatak University Dharwad, \\ Karnataka, India, 580003. \\ *Corresponding author e-mail: ashok_sidarai@rediffmail.com
}

\title{
Acknowledgment
}

The authors are grateful to the Director and Technical staff of USIC, Dharwad for giving the facility of Fluorescence spectrophotometer, UV-Vis spectrometer, and DSC instruments. We are also thankful to DST, New Dehli for providing FTIR spectrometer, particle size analyzer, and zeta potential instrument facility under the DST-PURSE-phase-II program. [Grant No.SR/PURSE PHASE-2/13(G)]. We acknowledge the Department of Biotechnology KU Dharwad for providing the facility of BIO-RAD molecular imaging system. 


\begin{abstract}
The fluorescence based applications such as chemosensing of $\mathrm{Fe}^{3+}$ ion, temperature sensing, NOR-gate molecular logic operations, and fluorescent ink were achieved using an expired medicine namely Pantoprazole (sensor 1 ) which is a derivative of benzimidazole class. The phenomenon of quenching was a basic principle used in sensing $\mathrm{Fe}^{3+}$. We found that there was a combined effect of dynamic and static processes in quenching of fluorescence of sensor1. To confirm the selectiveness of sensor1, we performed interference experiments with other metal ions. There was no interference between these metal ions and $\mathrm{Fe}^{3+}$. The low LOD value of $1.032 \mu \mathrm{M}$ suggested that the molecule is highly sensitive towards $\mathrm{Fe}^{3+}$. A high quantum yield of $8.087 \%$ increased the possibility of using sensor1 for light applications. There was a 2:1 stoichiometric ratio between sensor1 and $\mathrm{Fe}^{3+}$. The FTIR data analysis confirmed the presence of functional groups $\mathrm{S}=\mathrm{O}, \mathrm{C}-\mathrm{O}-\mathrm{C}$, etc. The average particle size found with the DLS method was $130.5 \mathrm{~nm}$. The zeta potential of $-12.7 \mathrm{mV}$ indicated that sensor1 is quite stable in solution form. For logic gate application EDTA (Ethylenediaminetetraaceticacid) and $\mathrm{Fe}^{3+}$ were considered as inputs and fluorescence intensity was taken as an output. In thermal sensing application, the high value of activation energy i.e $908 \mathrm{meV}$ and relative sensitivity of $1.2 \%{ }^{0} \mathrm{C}^{-1}$ affirmed that sensor 1 can be used for thermal applications. The sensor1 was also apt for fluorescent ink application. Hence this investigation deduced that sensor 1 can be a potential candidate for such applications over other conventional synthesized fluorescent probes.
\end{abstract}

Keywords: Expired medicine, $\mathrm{Fe}^{3+}$ sensor, Thermal sensor, NOR-gate, Fluorescent Ink. 


\section{Introduction}

The ascendancy of fluorescent sensors for the detection of metal ions lies in their high rate of selectiveness, sensitivity, non-toxicity, and reversibility. For this reason, there has been much assiduity on research and advancement of such chemosensors. Further, these can also be considered as substitutive for existing expensive, tardy detection methods like Inductive Coupling Plasma Mass Spectroscopy (ICP-MS), Flame Atomic Absorption Spectroscopy, (FAAS) etc. These molecular chemosensors change the color in presence of various metal ions such that detection can be easily done through visual observation. Among these detectable metal ions, $\mathrm{Fe}^{3+}$ plays a very far-reaching role in many biological and chemical systems. $\mathrm{Fe}^{3+}$ is essential to manage the homeostatic mechanism of the body. The deficit of $\mathrm{Fe}^{3+}$ can cause anaemia in humans. Over concentration of $\mathrm{Fe}^{3+}$ may lead to Parkinson's, Huntington's, and Alzheimer's diseases. [1-3] Hence it is essential to design fluorescent chemosensors for the detection of $\mathrm{Fe}^{3+}$. Even though there are many reports on $\mathrm{Fe}^{3+}$ to date, there is always a need for advancement in these sensors in terms of economic procedures for synthesis, non-toxicity, reversibility, etc. [4-6]

Temperature plays a vital role in all physical and biological systems. Molecular thermometers are procuring large consideration over conventional temperature detectors such as thermometers, thermistors, thermocouples, etc. This is because these detectors have many shortcomings like low resolution capacity, low sensitivity, less accuracy, etc. The molecular thermometers have many advantages of non-contact measurements, optical stability, fast response, high resolution, non-toxicity, etc. Hence the usage of such molecular thermometers is surging considerably in recent years. $[7,8]$

The idea of using fluorescent molecules for logic gates application was dawned in the early $90 \mathrm{~s}$. Since then there is a lot of development in the field. Based on changes in fluorescence intensities of molecules after adding quenchers, the logic gate operations can be judged. These logic devices can be reliable candidates for applications in medical diagnostics, Photo Dynamic Therapy, recognition of pathophisyological conditions, cryptography, etc. $[9,10]$ So there is a need for developing economic, accurate molecular logic devices.

Herein, we propose an uncommon idea to reuse an expired medicine namely Pantoprazole (Sensor1) which is highly fluorescent, stable, selective for $\mathrm{Fe}^{3+}$ metal ion, sensitive towards temperature, and can be applied for logic gate applications. Further, it has been also used for fluorescent ink application. Reworking on such fluorescent waste drugs can be advantageous and proper waste management can be expected. The study can be considered superior to previous reports since chemosensing, temperature sensing, logic gate, and fluorescent ink applications have been achieved by directly using the drug without any irksome synthesis procedures, toxic materials, expensive precursors, and precious time. The sensor 1 showed selectivity towards $\mathrm{Fe}^{3+}$ metal ion, temperature sensitiveness with a sensitivity of $1.21 \%{ }^{0} \mathrm{C}^{-1}$, NOR gate logic operations, and fluorescent ink application. Hence the drug can be an acceptable candidate for fluorescence applications. 


\section{Experimental}

\section{Materials and methods}

The medicine namely Pantoprazole (sensor 1 ) which has an expiry date of 04/2019 was used for the current study and to conduct experiments. Pantoprazole has a molecular weight of $383.4 \mathrm{~g} / \mathrm{mol}$ and molecular formula $\mathrm{C}_{16} \mathrm{H}_{15} \mathrm{~F}_{2} \mathrm{~N}_{3} \mathrm{O}_{4} \mathrm{~S}$. It melts at about $150^{\circ} \mathrm{C}$ and has a boiling point of $586.9^{\circ} \mathrm{C}$. Its IUPAC name is 6-(difluoromethoxy)-2-[(3,4-dimethoxypyridin-2$\mathrm{yl}$ )methylsulfinyl]- $1 \mathrm{H}$-benzimidazole. It belongs to benzimidazole class. It is a member of organofluorine, sulphoxide, aromatic ether, and pyridines. Pantoprazole is generally used in the treatment of stomach ulcers. [11] The compound was taken from a local shop City Drug House, Dharwad, Karnataka, India. The tablet was powdered finely using a mortar for conducting experiments.

The salts $\mathrm{NaCl}, \mathrm{CuCl}_{2} .2 \mathrm{H}_{2} \mathrm{O}, \mathrm{CoCl}_{2} \cdot 6 \mathrm{H}_{2} \mathrm{O}, \mathrm{HgCl}_{2}, \mathrm{KCl}, \mathrm{ZnCl}_{2}, \mathrm{FeCl}_{3}, \mathrm{PbCl}_{2}, \mathrm{MnCl}_{2} \cdot 4 \mathrm{H}_{2} \mathrm{O}, \mathrm{CaCl} 2, \mathrm{MgCl}_{2}$, $\mathrm{BaCl}_{2}, \mathrm{LiCl}, \mathrm{AgCl}, \mathrm{CdCl}_{2}$ were of analytical grade and purchased from Sisco Research Laboratories Pvt. Ltd. India. EDTA was bought from HiMedia Laboratories Pvt. Ltd. India. All purchased chemicals were ultrapure and used without any modifications. Highly pure distilled water was taken to perform all the experiments. The same room temperature that is $25^{\circ} \mathrm{C}$ was maintained throughout the investigation.

\section{Instrumentation}

Thermal measurements were done on DSC Q20 instrument. [USIC, Karnatak University Dharwad]. Particle size and zeta potential analysis was performed using nano particle size analyzer. [HORIBA Scientific, USIC, K U Dharwad.]For fluorescent ink application BIO-RAD molecular imaging system [Dept. of Biotecnology, $\mathrm{K} U$ Dharwad.] was used. FTIR data was taken on Thermo Scientific Nicolet iN10 IR Microscope. [USIC, Karnatak University Dharwad]. UV-Vis and fluorescence measurements were taken on UV-Vis [Hitachi 3310, USIC, Karnatak University Dharwad] and Fluorescence spectrometer [HitachiF7000,USIC, Karnatak University Dharwad] respectively.

\section{Results and analyzation}

\section{Detection and Sensing of $\mathrm{Fe}^{3+}$}

Highly stable sensor1 in an aqueous solution was used to detect the $\mathrm{Fe}^{3+}$ ion. The molecule was excited at $290 \mathrm{~nm}$ and it showed emission at $347 \mathrm{~nm}$, which indicates that there might be a $\pi-\pi^{*}$ transition. The solution of sensor1 was prepared with a concentration of $1 \times 10^{-4} \mathrm{M}$. Solutions of different metal ions namely $\mathrm{Co}^{2+}, \mathrm{Ca}^{2+}, \mathrm{Mg}^{2+}, \mathrm{Zn}^{2+}, \mathrm{Ba}^{2+}, \mathrm{K}^{+}, \mathrm{Na}^{+}, \mathrm{Mn}^{2+}, \mathrm{Hg}^{2+}$, $\mathrm{Pb}^{2+}, \mathrm{Cu}^{2+}, \mathrm{Cd}^{2+}, \mathrm{Ag}^{2+}, \mathrm{Li}^{2+}$ were prepared with a concentration of $1 \times 10^{-3} \mathrm{M}$ and titrated against sensor 1 separately. There was a minor change in intensity of sensor 1 with these ions. We observed minute enhancement in the intensity when $\mathrm{Ba}^{2+}, \mathrm{Cu}^{2+}, \mathrm{Li}^{2+}, \mathrm{Mn}^{2+}$ ions were added to sensor1. The metal ions other than these showed an inconsiderable decrease in intensity. 
This revealed that sensor 1 was not sensitive towards these ions. When $\mathrm{Fe}^{3+}$ ion was added to sensor1, we observed a sudden decrement in its intensity. This increased the probability of interaction between $\mathrm{Fe}^{3+}$ and sensor1. Further to affirm the sensitiveness of sensor1 we calculated the detection limit using the formula 3.3( $\sigma / \mathrm{S})$ [12] where $\sigma$ is the standard deviation and $\mathrm{S}$ is the slope of the calibration curve. The LOD was found to be $1.032 \mu \mathrm{M}$.

The selectivity of sensor 1 was confirmed by adding $\mathrm{Fe}^{3+}(1 \mathrm{mM})$ as 7 equivalents with $40 \mu \mathrm{L}$ each to the solution of sensor1. Each time when we added the $\mathrm{Fe}^{3+}$, there was a considerable reduction in the intensity of it. (Figure.1a) But this was not the same for other metal ions. We calculated the degree of reduced or enhanced intensities of sensor 1 by each metal ion. Except for $\mathrm{Fe}^{3+}(99.18 \%)$ all other ions showed less percentage of quenching efficacies, i.e we witnessed the increase of fluorescence intensities in cases of $\mathrm{Ba}^{2+}, \mathrm{Cu}^{2+}$, $\mathrm{Li}^{2+}, \mathrm{Mn}^{2+}$ by $5.45 \%, 30.41 \%, 9.71 \%, 2.15 \%$ respectively. There was a quenching effect in cases of $\mathrm{Ca}^{2+}, \mathrm{Mg}^{2+}, \mathrm{Na}^{+}, \mathrm{Hg}^{2+}, \mathrm{Co}^{2+}, \mathrm{K}^{+}, \mathrm{Zn}^{2+}, \mathrm{Cd}^{2+}, \mathrm{Pb}^{2+}, \mathrm{Ag}^{2+}$ by $0.5 \%, 2.66 \%, 0.46 \%, 14.90 \%$, $5.94 \%, 5 \%, 14.73 \%, 3.79 \%, 4.26 \%, 3.49 \%$ respectively. Hence it was deduced that sensor 1 was selective and sensitive for $\mathrm{Fe}^{3+}$. Further, we also performed the interference test for sensor1. The solution of sensor 1 was added with the solutions of different above mentioned metal ions. We didn't find any interference between $\mathrm{Fe}^{3+}$ and other metal ions. The histogram shows the comparison of blank and other metal ions. (Figure.1b)

The optical and physical stabilities are the most important properties that fluorescent sensors should have. We examined sensor1 for its physical stability. The solution of sensor 1 was kept for observation for about 50 days. The intensity measurement was taken once in 7 days. We didn't observe any major changes in intensity. (figure.1c) Different increasing concentrations starting from $0.2 \mathrm{mM}$ to $1.2 \mathrm{mM}$ were added to sensor1, there was no shift in emission wavelength of it. (figure.1d) Hence it can be assumed that the sensor 1 can be used for different chemical and physical applications. [12]

\section{Job's plot}

To get an insight on stoichiometry between sensor 1 and $\mathrm{Fe}^{3+}$ ion, Job's method was used. The volumetric ratios of sensor 1 and $\mathrm{Fe}^{3+}$ were varied from 0.3 to $2.7 \mathrm{ml}$ and 2.7 to $0.3 \mathrm{ml}$ respectively. The total concentration of sensor 1 and $\mathrm{Fe}^{3+}$ was $10^{-3} \mathrm{M}$. The graph of intensity Vs $\left[\mathrm{Fe}^{3+}\right] /\left([\right.$ Sensor 1$\left.]+\left[\mathrm{Fe}^{3+}\right]\right)$ was plotted. The graph showed maximum intensity point at 0.3 on X-axis. (figure.2)Hence there must be a 2:1 stoichiometric ratio between sensor 1 and $\mathrm{Fe}^{3+} \cdot[13,14]$

\section{Quantum Yield}

The quantum yield was calculated using the single point method. Tryptophan was chosen as a reference with absorbance 3.009 at $270 \mathrm{~nm}$ and emission at $337 \mathrm{~nm}$. The literature quantum yield of Tryptophan was found to be 0.15 at $270 \mathrm{~nm}$. The quantum yield was calculated by the following equation,[15-17] 


$$
\mathrm{Q}=\mathrm{Q}_{R}\left(\frac{\mathrm{I}}{\mathrm{I}_{\mathrm{R}}}\right)\left(\frac{\mathrm{A}_{R}}{A}\right)\left(\frac{n^{2}}{n_{R}^{2}}\right)
$$

Where $\mathrm{Q}_{R}$ is the quantum yield of standard reference, I and $\mathrm{I}_{\mathrm{R}}$ are integrated fluorescence intensities of sample and reference respectively. $\mathrm{A}_{R}$ and $A$ are the absorbance of reference and sample. $n$ and $n_{R}$ are Rls of sample and reference respectively. The calculated quantum yield was found to be $8.087 \%$.

\section{FTIR analysis}

The presence of functional groups such as $\mathrm{S}=\mathrm{O}, \mathrm{N}-\mathrm{H}, \mathrm{C}-\mathrm{O}-\mathrm{C}$, etc. In sensor1 was confirmed by performing FTIR analysis. (figure.3)The peak at $3368.75 \mathrm{~cm}^{-1}$ may be attributed to the stretching vibrations of the $\mathrm{N}-\mathrm{H}$ group. The absorption peaks at $2922.37 \mathrm{~cm}^{-1}, 1616.82 \mathrm{~cm}^{-1}$ , $1551.86 \mathrm{~cm}^{-1}$ represent the stretching modes of $\mathrm{C}-\mathrm{H}, \mathrm{C}=\mathrm{N}, \mathrm{C}=\mathrm{C}$ bonds. [1,12] The bands in the range $1460 \mathrm{~cm}^{-1}$ to $1017 \mathrm{~cm}^{-1}$ represent the vibrations of $\mathrm{C}-\mathrm{N}, \mathrm{C}-\mathrm{O}, \mathrm{C}-\mathrm{S}$, and $\mathrm{C}-\mathrm{H}$ bonds respectively. The peak at $1337.33 \mathrm{~cm}^{-1}$ represents the stretching of the $\mathrm{S}=\mathrm{O}$ group. Peaks in the range $916 \mathrm{~cm}^{-1}$ to $713 \mathrm{~cm}^{-1}$ represented the bending vibrations of $\mathrm{C}=\mathrm{C}, \mathrm{C}-\mathrm{H}$ bonds. [18, 19]

\section{Quenching Analysis}

The solution of sensor 1 was prepared with a concentration of $1 \times 10^{-4} \mathrm{M}$. The fluorescence intensity of sensor 1 was highly quenched with the addition of $\mathrm{Fe}^{3+} .\left(1 \times 10^{-3}\right)$ Initiating with $40 \mu \mathrm{L}$ seven equivalents were added to sensor1, we observed considerable decrement in intensity. To predict the type of quenching we took the help of the Stern-Volmer relation which defines the dependency of intensity with change in concentration. The plot of $F_{0} / F$ Vs $\left[\mathrm{Fe}^{3+}\right]$ was plotted and was analyzed by the following equation,[20]

$$
\frac{\mathrm{F} 0}{\mathrm{~F}}=1+\mathrm{Ksv}[\mathrm{Q}]
$$

where $\mathrm{F}_{0}$ and $\mathrm{F}$ are fluorescence intensity without and with quencher i.e $\mathrm{Fe}^{3+}$. Ksv is the Stern-Volmer constant and [Q] is the concentration of quencher. This plot showed a bend towards the $Y$ axis, which indicated that the lessening of intensity was not only due to collision between sensor1 and $\mathrm{Fe}^{3+}$. (figure.4a)There may be also a likeliness of complex formation in the excited state. Added, to confirm our assumption that quenching was not only due to the dynamic process, the graph of $\left[\left(\frac{\mathrm{F} 0}{\mathrm{~F}}\right)-1\right] /[\mathrm{Q}] \mathrm{Vs}\left[\mathrm{Fe}^{3+}\right]$ was plotted. (figure.4b)This graph accounts for modified S-V equation,

$$
\frac{\left(\frac{\mathrm{F} 0}{\mathrm{~F}}-1\right)}{[\mathrm{Q}]}=(\mathrm{Ksv}+\mathrm{Kg})+(\mathrm{Ksv} * \mathrm{Kg})[\mathrm{Q}]
$$

where $F_{0},[Q], K s v$ are having the usual meaning. $K_{g}$ is the ground state association constant. The graph was a straight line with an intercept value of $-7.803(\mathrm{Ksv}+\mathrm{Kg}$ ) and the slope of 83.76 ( $\mathrm{Ksv} * \mathrm{Kg})$. The data acquired using this model was imaginary and we used the 
sphere of action quenching model to get the $\mathrm{K}_{s v}$ value. The modified S-V equation can be given as

$$
\frac{1-\frac{\mathrm{F}}{\mathrm{F} 0}}{[\mathrm{Q}]}=\operatorname{Ksv}\left(\frac{\mathrm{F}}{\mathrm{F} 0}\right)+\left(\frac{1-\mathrm{W}}{[\mathrm{Q}]}\right)
$$

$\mathrm{W}$ is the fraction of fluorophores quenched because of dynamic interaction in the excited state. The graph of $\frac{1-\frac{\mathrm{F}}{\mathrm{F} 0}}{[\mathrm{Q}]}$ Vs $\frac{\mathrm{F}}{\mathrm{F} 0}$ was a straight line with a nearly unit correlation coefficient. (figure.4c)The slope of the graph was taken as $\mathrm{K}_{\mathrm{sv}}$ value and was found to be $8.76 \times 10^{3} \mathrm{M}^{-1}$. This study suggested that there might be a combined effect of dynamic and static processes which is responsible for quenching of the intensity of sensor $1 .[21,22]$

\section{Possible mechanism of binding}

As previously studied quenching of fluorescence of sensor 1 may be due to the combined effect of complex formation and collision between the functional groups $\mathrm{C}-\mathrm{O}-\mathrm{C}$ or $\mathrm{S}=\mathrm{O}$ etc of sensor1 and $\mathrm{Fe}^{3+}$. $\mathrm{Fe}^{3+}$ has shown a high chelating effect towards these functional groups, hence considerable quenching was observed. [23] There is also a possibility of non-radiative transfer of energy or electrons from excited states of sensor 1 to half filled $3 d^{5}$ states of $\mathrm{Fe}^{3+}$. [1]

\section{Physical properties of sensor1}

To predict the size of the Sensor1, Dynamic Light Scattering (DLS) measurements were performed. The molecule had an average size of $130.5 \mathrm{~nm}$. The experiment was performed at a scattering angle of $90^{\circ}$ and in mono-dispersed distribution form. $10 \%$ of total particles had approximately a size of $121.9 \mathrm{~nm}, 50 \%$ had $163.4 \mathrm{~nm}$ with a mean size of $169.4 \mathrm{~nm}$. (figure.5a) Further, to know the flocculation rate (Stability of the solution) of the suspension, we measured the zeta potential. The value of $-12.7 \mathrm{mV}$, indicated that the particles are stable and they take a longer time to agglomerate in solution form.[24-26] (Figure.5b) The energy bandgap of the sensor1 was determined using Tauc's method. (figure.5c) Exponent value $\mathrm{n}=0.5$ was taken which is meant for the indirect type of transition. The band gap was estimated to be 3.89eV. [27-29]Added, to confirm the melting point and to gather the thermal information of the material we performed DSC measurements. There was negligible mass loss up to the temperature of $150^{\circ} \mathrm{C}$. But the curve in the range $150^{\circ} \mathrm{C}-215^{\circ} \mathrm{C}$ shows that there was an abrupt release of energy and weight loss of the sensor1. We observed the least mass loss in the range $240-300^{\circ} \mathrm{C}$. The DSC peaks are shown in figure.5d [30, 31] 


\section{Logic gate application}

To investigate logic gate application with sensor1, we conducted an experiment including sensor $1, \mathrm{Fe}^{3+}$, and EDTA. Concentrations with $1 \times 10^{-4} \mathrm{M}, 1 \times 10^{-3} \mathrm{M}$ and $1 \times 10^{-3} \mathrm{M}$ of sensor 1 , $\mathrm{Fe}^{3+}$, and EDTA (A mixture of THF(Tetrahydrofuran) and water in a 1:1 ratio) were prepared respectively. The intensity of sensor 1 at $347 \mathrm{~nm}$ emission wavelength was recorded. The intensity dropped considerably when $\mathrm{Fe}^{3+}(40 \mu \mathrm{l})$ were added to the solution of sensor 1. However, when the chelating agent EDTA was added, we observed a bit of enhancement in emission intensity. But this increment was inconsiderable and was below the threshold value. Hence we considered it as a ' 0 ' output value. When $\mathrm{Fe}^{3+}$ was added again to this solution we noticed a further drop in intensity. The threshold value was set to 666 a.u. $\mathrm{Fe}^{3+}$ and EDTA was considered as inputs and the resulting emission intensity was taken as output. The intensity above threshold value was taken as output value ' 1 ' and the intensity below threshold value was taken as ' 0 ' output value. The results resembled the outputs of the 'NOR' logic gate. (Figure.6). Thus we can assume that sensor1 can be used for the application of molecular logic gates, keypads, switches, etc. [10, 32, 33]

\section{Application in temperature sensing}

For the appraisal of temperature sensing behavior of sensor1, we observed the intensities of sensor 1 at temperatures ranging from $25^{\circ} \mathrm{C}$ to $70^{\circ} \mathrm{C}$. Interestingly sensor 1 was very much sensitive towards increasing temperatures owing to the fact that it can be used as a molecular thermometer in the physiological temperature range. As the temperature rose from $25^{\circ} \mathrm{C}$ to $70^{\circ} \mathrm{C}$ we observed a decrement of $54.55 \%$ intensity with a sensitivity of $1.21 \%$ ${ }^{0} \mathrm{C}^{-1}$. We also noticed that there was negligible or no shift in emission wavelength $(347 \mathrm{~nm})$ with the increment in temperature. (figure.7a)The intensity showed good linear relation

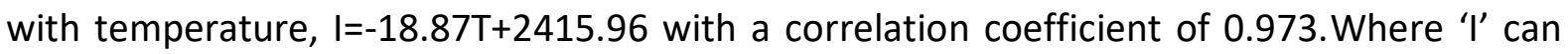
be indicated as fluorescence intensity and ' $T$ ' as temperature. (Figure.7b) The domination of non-radiative decays, enhancement of mobility, and collision rate of molecules at higher temperatures could be the reason for the reduction in the intensity. For the affirmation of reversibility of sensor 1 , consecutive heating and cooling experiments were performed. The sensor1 solution was first cooled to $15^{\circ} \mathrm{C}$ and the corresponding intensity was noted down. Further, the temperature was raised to $50^{\circ} \mathrm{C}$ and again the intensity was recorded. This procedure was repeated for five cycles and the Intensity Vs number of cycles graph was plotted. [34] The results were obtained as intended. (Figure.7c)

To look over the sensitiveness of the sensor 1 towards temperature, we used the Arrhenius equation for finding activation energy. The expression goes as

$$
\frac{\mathrm{F}_{0}}{\mathrm{~F}}=1+\mathrm{A} \exp \left(\frac{-\mathrm{E}_{a}}{\mathrm{~K}_{\mathrm{B}} \mathrm{T}}\right)
$$

$\mathrm{T}, \mathrm{F}_{0}$, and $\mathrm{F}$ have the usual meaning. $\mathrm{A}$ is a dimensionless constant, $\mathrm{E}_{a}$ is activation energy and $K_{B}$ is Boltzmann's constant. The graph of $\ln \left(F_{0} / F-1\right)$ Vs $1 / K_{B} T$ gave a straight line with an 
activation energy value of $908 \mathrm{meV}$ which was much higher than previously reported values.(Figure.7d) Hence we can say that sensor1 is more sensitive towards temperature than any other reported sensors. Thus reversibility, sensitiveness, non-toxicity, wide range of temperature for detection makes sensor 1 a good candidate for the application of molecular thermosensing. [35, 36]

\section{As Fluorescent ink}

Satisfying PL stability, solubility, high fluorescence, and non-venomous properties of sensor1 made us use it for fluorescent ink application. In recent periods traditional inks which are used in information storage and encryption, document labeling, etc are being replaced by fluorescent inks, hence are gaining more attention. For this application, the aqueous solution of sensor1 with a concentration of $1 \mathrm{M}$ was prepared and the word 'INK' was written on Whatman filter paper. (figure.8)The characters were invisible under daylight and visible under $350 \mathrm{~nm}$ UV light. This investigation made sensor1 apt for fluorescent ink application. [3, 37-39]

\section{Conclusion}

This research work can be completed with a deduction that the highly fluoregenic waste/expired medicine namely Pantoprazole (sensor1) can be directly reused for fluorescence applications like $\mathrm{Fe}^{3+}$ sensing, logic gate application, temperature sensing, and fluorescent ink application. The physical stabilities of sensor1 were confirmed by zeta potential and DSC studies. Further, to get a deep insight into molecule FTIR analysis, DLS measurements were performed. The 2:1 stoichiometry between molecule and $\mathrm{Fe}^{3+}$ suggested the formation of a non-fluorescent complex between these two. The lower value of LOD i.e $1.032 \mu \mathrm{M}$ confirmed sensor1 was sensitive towards $\mathrm{Fe}^{3+}$. The activation energy of $908 \mathrm{meV}$ implied that sensor 1 can be used for thermal sensing applications. As there is no synthesis procedure involved in this method, this can be too economic and less time consuming. Hence this report can be considered as superior to previous reports in which tardy and expensive methods are involved.

\section{Author Declarations}

\section{Funding}

Not applicable

\section{Conflicts of interest}

Not applicable

\section{Ethics approval}

Not applicable 


\section{Consent to participate}

Not applicable

\section{Consent to publication}

Not applicable

\section{Availability of data and material}

Not applicable

\section{Code availability}

Not applicable

\section{Authors' contributions}

Materials and data collection, analysis of data and draft of the article was done by Ms.Aishwarya Nadgir. Review, editing, project administration and supervision of the work were done by Dr. Ashok H. Sidarai.

\section{References}

1. N.Murugan and A.K.Sundramoorthy, Green synthesis of fluorescent carbon dots from Borassus flabellifer flower for label-free highly selective and sensitive detection of Fe3+ ions, New Journal of Chemistry, DOI:10.1039/C8NJ01894D.

2. Joshi S, Kumari S, Sarmah A, Sakhuja R, Pant DD (2016) Solvatochromic shift and estimation of dipole moment of synthesized coumarin derivative: Application as sensor for fluorogenic recognition of $\mathrm{Fe} 3+$ and $\mathrm{Cu} 2+$ ions in aqueous solution. Journal of Molecular Liquids 222:253-262 https://doi.org/10.1016/j.molliq.2016.07.047

3. Xu D, Lei F, Chen H, Yin L, Shi Y, Xie J (2019) properties of self-quenching-resistant carbon dots. 8290-8299. https://doi.org/10.1039/c8ra10570g

4. Li Z, Li H, Shi C, Zhang W, Zhou W, Wei L, Yu M (2015) Ac ce $p$ te $d \mathrm{cr}$ t. Sensors \& Actuators: B Chemical. https://doi.org/10.1016/j.snb.2015.11.105

5. Hu Y, Zhao F, Hu S, Dong Y, Li D, Su Z (2017) A novel turn-on colorimetric and fluorescent sensor for $\mathrm{Fe} 3+$ and its application in living cells. Journal of Photochemistry and Photobiology A: Chemistry 332:351-356 . https://doi.org/10.1016/j.jphotochem.2016.09.006

6. Y.Ding and C.Zhao, (2018) A Highly Selective Fluorescent Sensor For Detection Of Trivalent Metal Ions Based On A Simple Schiff-Base Quimica Nova ,41, 623-627. 
7. Brites CDS, Lima PP, Carlos LD (2016) Tuning the sensitivity of Ln3+-based luminescent molecular thermometers through ligand design. Journal of Luminescence 169:497-502 . https://doi.org/10.1016/j.jlumin.2015.01.025

8. Zhu C, Long Z, Wang Q, Qiu J, Zhou J, Zhou D, Wu H, Zhu R (2019) Insights into antithermal quenching of photoluminescence from SrCaGa 408 based on defect state and application in temperature sensing. Journal of Luminescence 208:284-289 . https://doi.org/10.1016/j.jlumin.2018.12.063

9. Erbas-Cakmak S, Kolemen S, Sedgwick AC, Gunnlaugsson T, James TD, Yoon J, Akkaya EU (2018) Molecular logic gates: The past, present and future. Chemical Society Reviews 47:2228-2248 . https://doi.org/10.1039/c7cs00491e

10. Yousuf S, Alex R, Selvakumar PM, Enoch IVMV, Subramanian PS, Sun Y (2015) Picking Out Logic Operations in a Naphthalene $\beta$-Diketone Derivative by Using Molecular Encapsulation, Controlled Protonation, and DNA Binding. ChemistryOpen 4:497-508 . https://doi.org/10.1002/open.201500034

11. NIH-National of Library Medicine, PubChem, https://pubchem.ncbi.nlm.nih.gov/compound/4679, Last accessed in February 2021.

12. Sharma V, Kaur N, Tiwari P, Saini AK, Mobin SM (2018) SC. Multifunctional fluorescent "Off-On-Off" nanosensor for Au3+ and S2-employing N-S co-doped carbon-dots, Carbon. https://doi.org/10.1016/j.carbon.2018.07.004

13. Qais FA, Abdullah KM, Alam MM, Naseem I, Ahmad I (2017) Interaction of capsaicin with calf thymus DNA: A multi-spectroscopic and molecular modelling study. International Journal of Biological Macromolecules 97:392-402 . https://doi.org/10.1016/j.ijbiomac.2017.01.022

14. Wang W, Yuan WJ, Liu QL, Lei YN, Qi S, Gao Y (2014) Selective fluorescence sensor for Cu2+ with a novel triazole Schiff-base derivative with coumarin units. Heterocyclic Communications 20:289-292 . https://doi.org/10.1515/hc-2014-0117

15. Sahu S, Behera B, Maiti TK, Mohapatra S (2012) Simple one-step synthesis of highly luminescent carbon dots from orange juice: Application as excellent bio-imaging agents. Chemical Communications 48:8835-8837 https://doi.org/10.1039/c2cc33796g

16. Liu W, Diao H, Chang H, Wang H, Li T, Wei W (2017) Sensors and Actuators B : Chemical Green synthesis of carbon dots from rose-heart radish and application for Fe 3 + detection and cell imaging. Sensors \& Actuators: B Chemical 241:190-198 . https://doi.org/10.1016/j.snb.2016.10.068

17. Brouwer AM (2011) Standards for photoluminescence quantum yield measurements in solution (IUPAC technical report). Pure and Applied Chemistry 83:2213-2228 . https://doi.org/10.1351/PAC-REP-10-09-31

18. Roy P, Periasamy AP, Chuang C, Liou YR, Chen YF, Joly J, Liang C Te, Chang HT (2014) Plant leaf-derived graphene quantum dots and applications for white LEDs. New 
Journal of Chemistry 38:4946-4951 . https://doi.org/10.1039/c4nj01185f

19. Sigma aldrich, IR spectrum, Table and chart,https://www.sigmaaldrich.com/technicaldocuments/articles/biology/ir-spectrum-table.html, Last accessed in February 2021.

20. Nirupama JM, Khanapurmath NI, Chougala LS, Shastri LA, Bhajantri RF (2019) Effect of amino anilines on the fluorescence of coumarin derivative. Journal of Luminescence 208:164-173 . https://doi.org/10.1016/j.jlumin.2018.12.038

21. Molecular Fluorescence Principles and Application, Bemard Valeur, Wiley Publishers, 2001.

22. Principles of Fluorescence Spectroscopy, Joseph Lakowicz, Third Edition, Springer Publishers, 2006.

23. Wei G, Zhao Z, Du J, Li P, Sun Z, Huo L, Gao Y (2019) Reed-derived fluorescent carbon dots as highly selective probes for detecting Fe3+ and excellent cell-imaging agents. RSC Advances 9:21715-21723 . https://doi.org/10.1039/c9ra01841g

24. Raja S, Ramesh V, Thivaharan V (2017) Green biosynthesis of silver nanoparticles using Calliandra haematocephala leaf extract, their antibacterial activity and hydrogen peroxide sensing capability. Arabian Journal of Chemistry 10:253-261 . https://doi.org/10.1016/j.arabjc.2015.06.023

25. Xu Q, Kuang T, Liu Y, Cai L, Peng X, Sreenivasan Sreeprasad T, Zhao P, Yu Z, Li N (2016) Heteroatom-doped carbon dots: synthesis, characterization, properties, photoluminescence mechanism and biological applications. Journal of Materials Chemistry B 4:7204-7219 . https://doi.org/10.1039/C6TB02131J

26. Mikac L, Ivanda M, Gotić M, Mihelj T, Horvat L (2014) Synthesis and characterization of silver colloidal nanoparticles with different coatings for SERS application. Journal of Nanoparticle Research 16: . https://doi.org/10.1007/s11051-014-2748-9

27. Russo C, Apicella B, Lighty JS, Ciajolo A, Tregrossi A (2017) Optical properties of organic carbon and soot produced in an inverse diffusion flame. Carbon 124:372-379 . https://doi.org/10.1016/j.carbon.2017.08.073

28. Guayaquil-Sosa JF, Serrano-Rosales B, Valadés-Pelayo PJ, de Lasa H (2017) Photocatalytic hydrogen production using mesoporous TiO2 doped with Pt. Applied $\begin{array}{llll}\text { Catalysis } & \text { B: } & \text { Environmental }\end{array}$ https://doi.org/10.1016/j.apcatb.2017.04.029

29. Wang S, Li C, Wang T, Zhang P, Li A, Gong J (2014) Controllable synthesis of nanotubetype graphitic C3N 4 and their visible-light photocatalytic and fluorescent properties. Journal of Materials Chemistry A 2:2885-2890 . https://doi.org/10.1039/c3ta14576j

30. Kannan SK, Sundrarajan M (2014) A Green Approach for the Synthesis of a Cerium Oxide Nanoparticle: Characterization and Antibacterial Activity. International Journal of Nanoscience 13:1450018 . https://doi.org/10.1142/S0219581X14500185

31. Deng W, Chen D, Hu J, Chen L (2015) A general and green approach to synthesize 
monodisperse ceria hollow spheres with enhanced photocatalytic activity. RSC Advances 5:80158-80169 . https://doi.org/10.1039/c5ra15602e

32. Kumar P, Kumar V, Gupta R (2015) Arene-based fluorescent probes for the selective detection of iron. RSC Advances 5:97874-97882 . https://doi.org/10.1039/c5ra20760f

33. Tamil Selvan G, Varadaraju C, Tamil Selvan R, Enoch IVMV, Mosae Selvakumar P (2018) On/Off Fluorescent Chemosensor for Selective Detection of Divalent Iron and Copper lons: Molecular Logic Operation and Protein Binding. ACS Omega 3:79857992 . https://doi.org/10.1021/acsomega.8b00748

34. Yue D, Zhang J, Zhao D, Lian X, Cui Y, Yang Y, Qian G (2016) Ratiometric near infrared luminescent thermometer based on lanthanide metal-organic frameworks. Journal of Solid State Chemistry 241:99-104 . https://doi.org/10.1016/j.jssc.2016.06.005

35. Zhang Y, Guo X, Li G, Zhang G (2019) Photoluminescent Ag nanoclusters for reversible temperature and $\mathrm{pH}$ nanosenors in aqueous solution. Analytical and Bioanalytical Chemistry 411:1117-1125 . https://doi.org/10.1007/s00216-018-1541-5

36 Wan Y, Cui Y, Yang Y, Qian G (2018) Dye confined in metal-organic framework for twophoton fluorescent temperature sensing. Microporous and Mesoporous Materials 268:202-206. https://doi.org/10.1016/j.micromeso.2018.04.032

37 Zhu L, Yin Y, Wang CF, Chen S (2013) Plant leaf-derived fluorescent carbon dots for sensing, patterning and coding. Journal of Materials Chemistry C 1:4925-4932 . https://doi.org/10.1039/c3tc30701h

38 Bhatt S, Bhatt M, Kumar A, Vyas G, Gajaria T, Paul P (2018) Green route for synthesis of multifunctional fluorescent carbon dots from Tulsi leaves and its application as $\mathrm{Cr}(\mathrm{VI})$ sensors, bio-imaging and patterning agents. Colloids and Surfaces B: Biointerfaces 167:126-133 . https://doi.org/10.1016/j.colsurfb.2018.04.008

39 Issa MA, Abidin ZZ, Sobri S, Rashid SA, Mahdi MA, Ibrahim NA (2020) Fluorescent recognition of $\mathrm{Fe} 3+$ in acidic environment by enhanced-quantum yield $\mathrm{N}$-doped carbon dots: optimization of variables using central composite design. Scientific Reports 10:1-18 . https://doi.org/10.1038/s41598-020-68390-8 
Figures
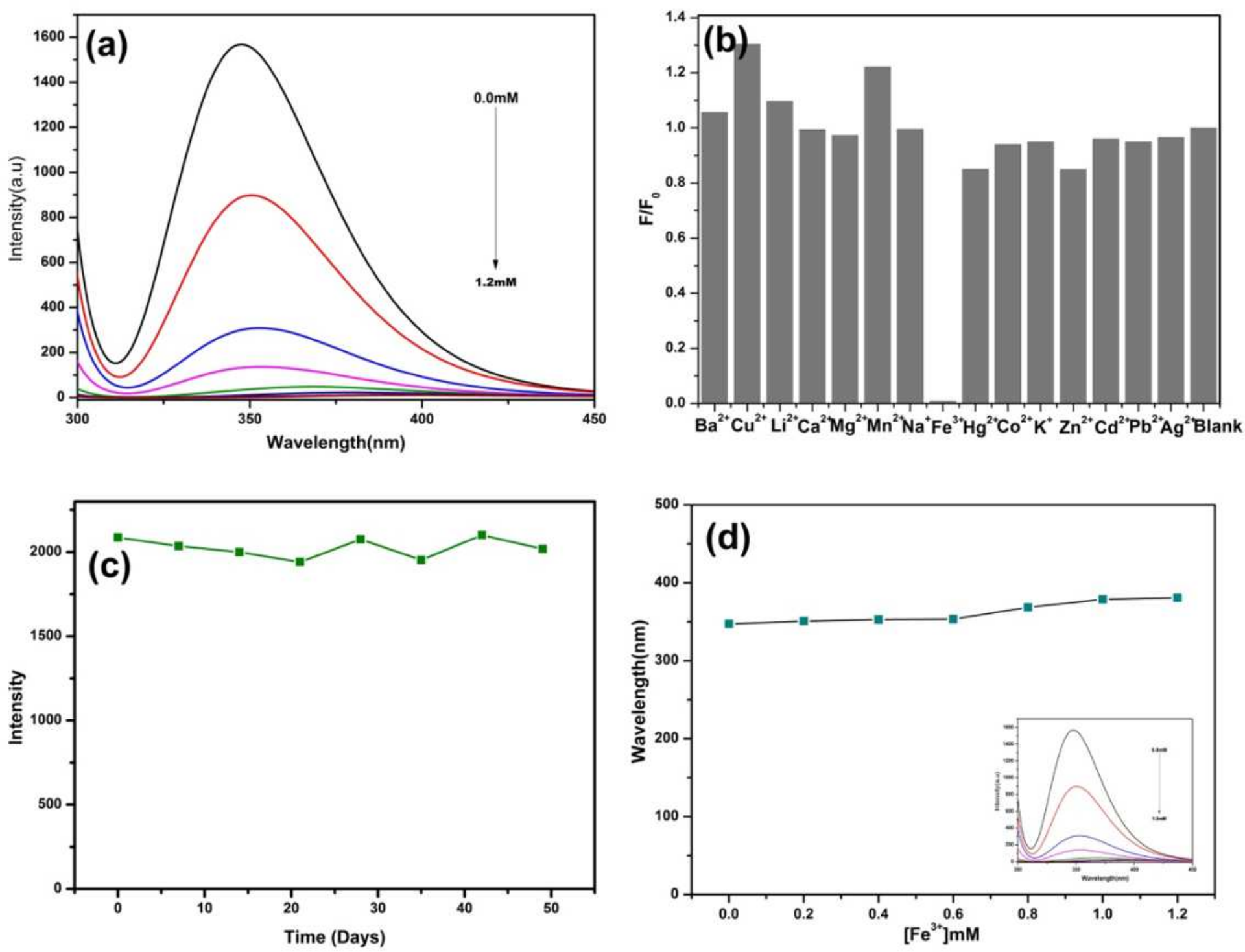

Figure 1

(a) Reduced fluorescence intensities of Sensor1 with increasing concentrations of Fe3+. (b) Histogram comparing relative intensities of sensor1 with blank and other metal ions. (c) Intensities of sensor1 relative to time i.e days (d) Graph indicating no change in emission wavelength with addition of enhanced concentrations of Fe3+ 


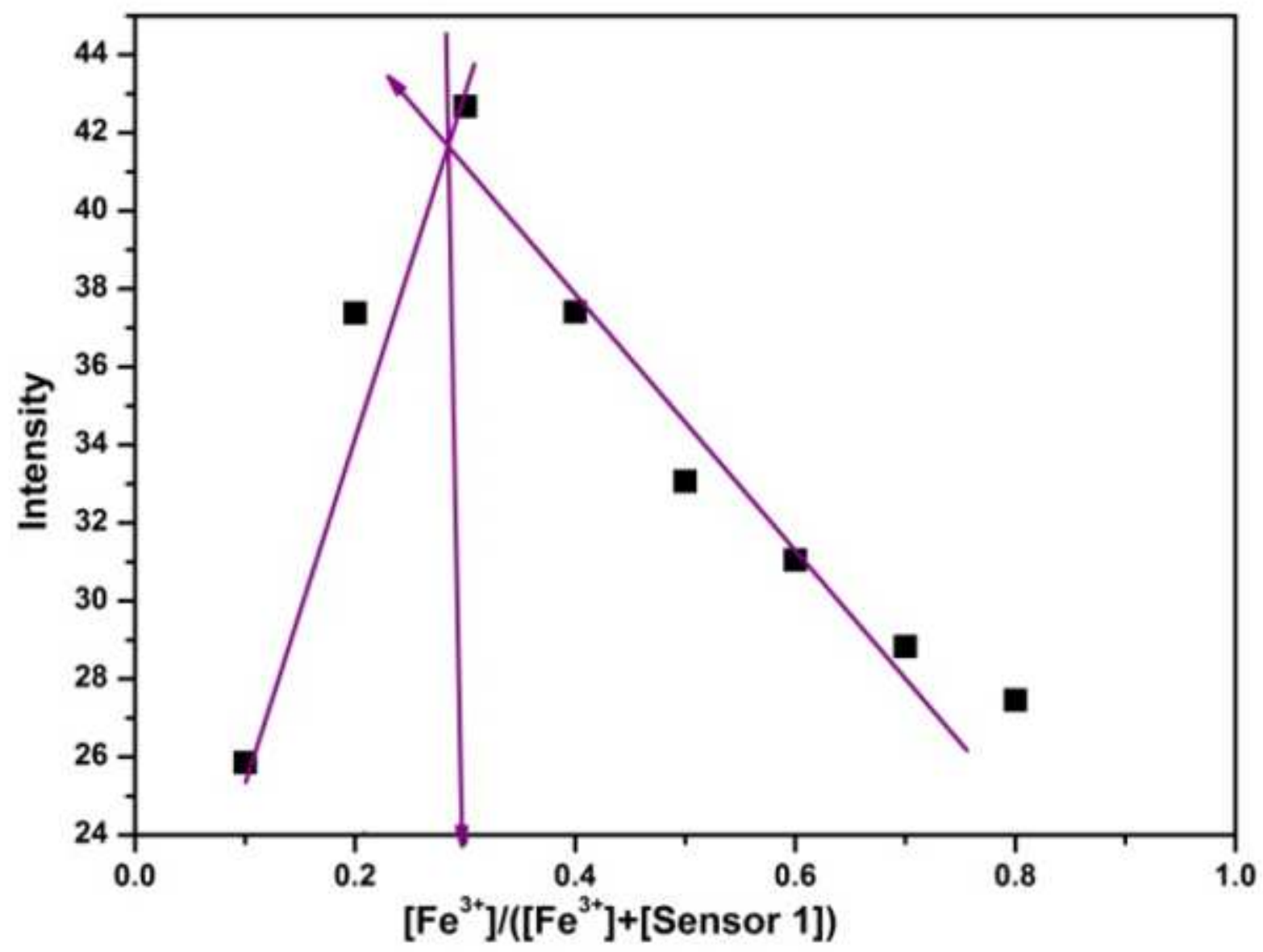

Figure 2

Job's plot of intensities plotted against mole fraction of $\mathrm{Fe} 3+$ 


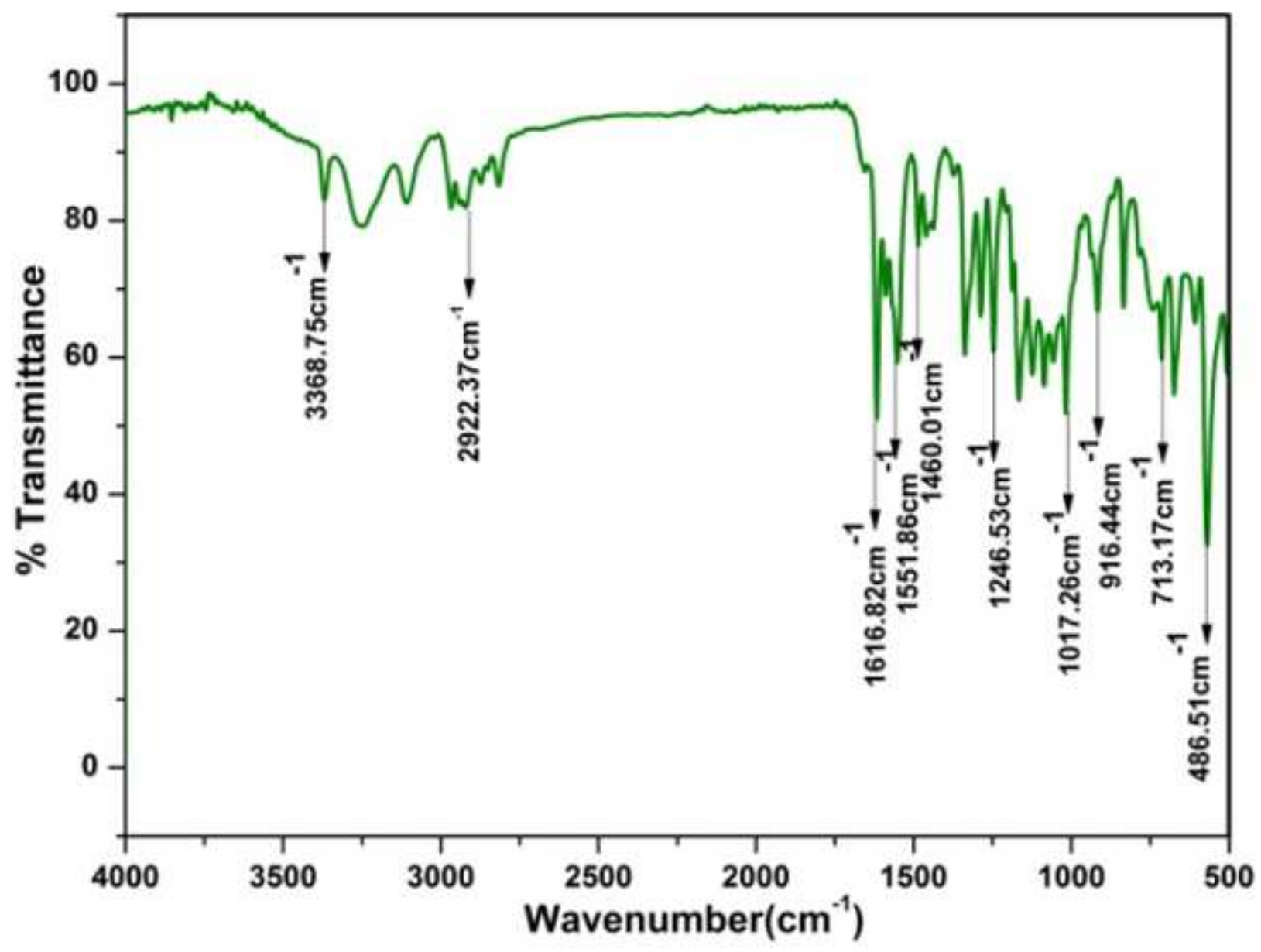

Figure 3

FTIR spectrum of sensor1.
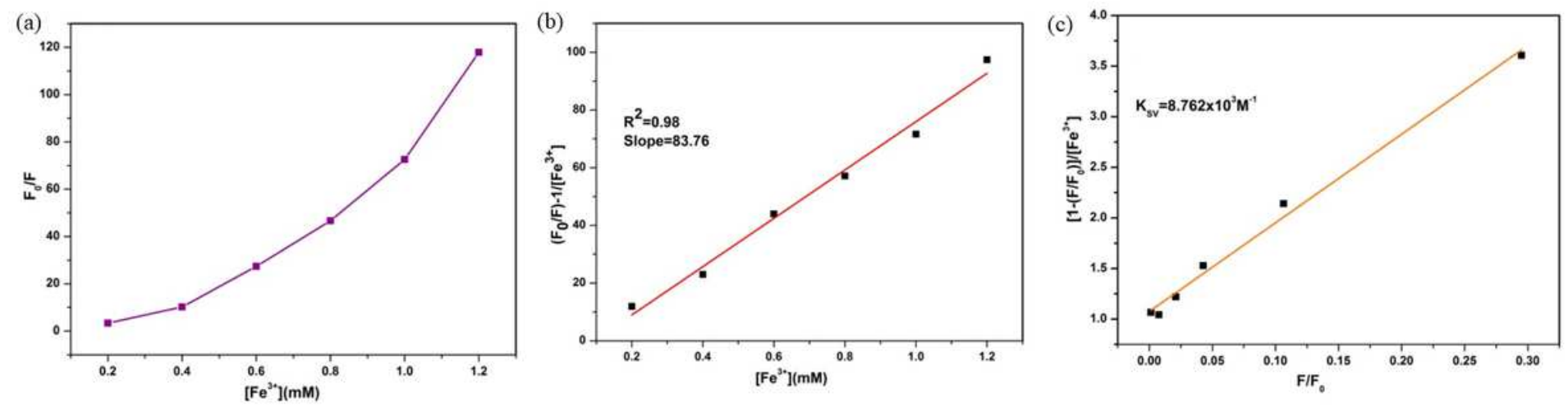

Figure 4

(a) Graph showing bending of F0/F curve towards $\mathrm{Y}$ axis when plotted in contrast to concentrations of Fe3+. (b) Modified Stern-Volmer plot. (c) Graph of (1-F/F0)/([Q]) Vs F/F0 which affirms the combined effect of static and dynamic quenching. 

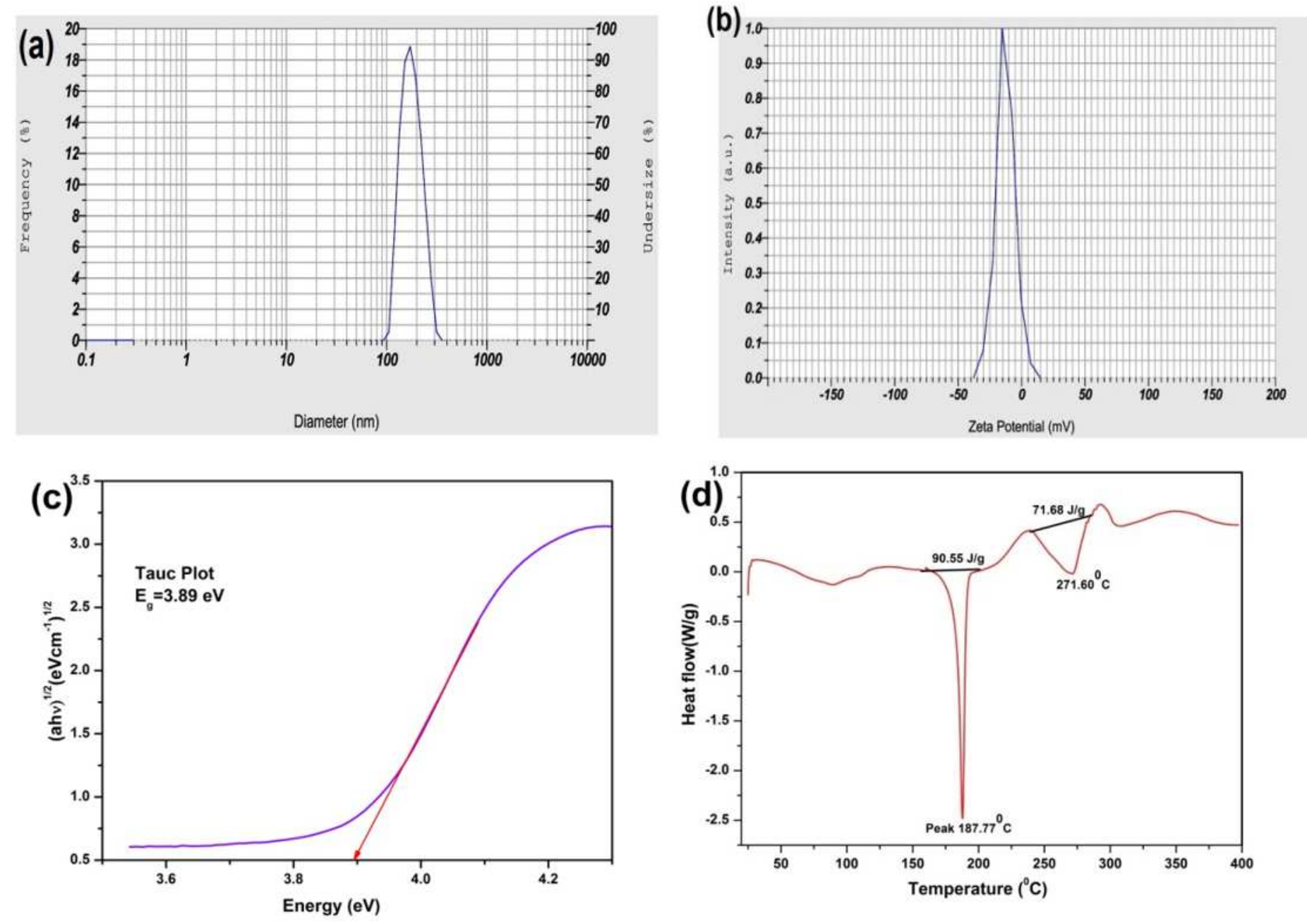

Figure 5

(a) Particle size distribution curve of sensor1. (DLS method) (b) Graph exploring zeta potential of sensor1. (c) Tauc's plot demonstrating energy gap of sensor1. (d) DSC curve showing weight loss points of sensor1. 


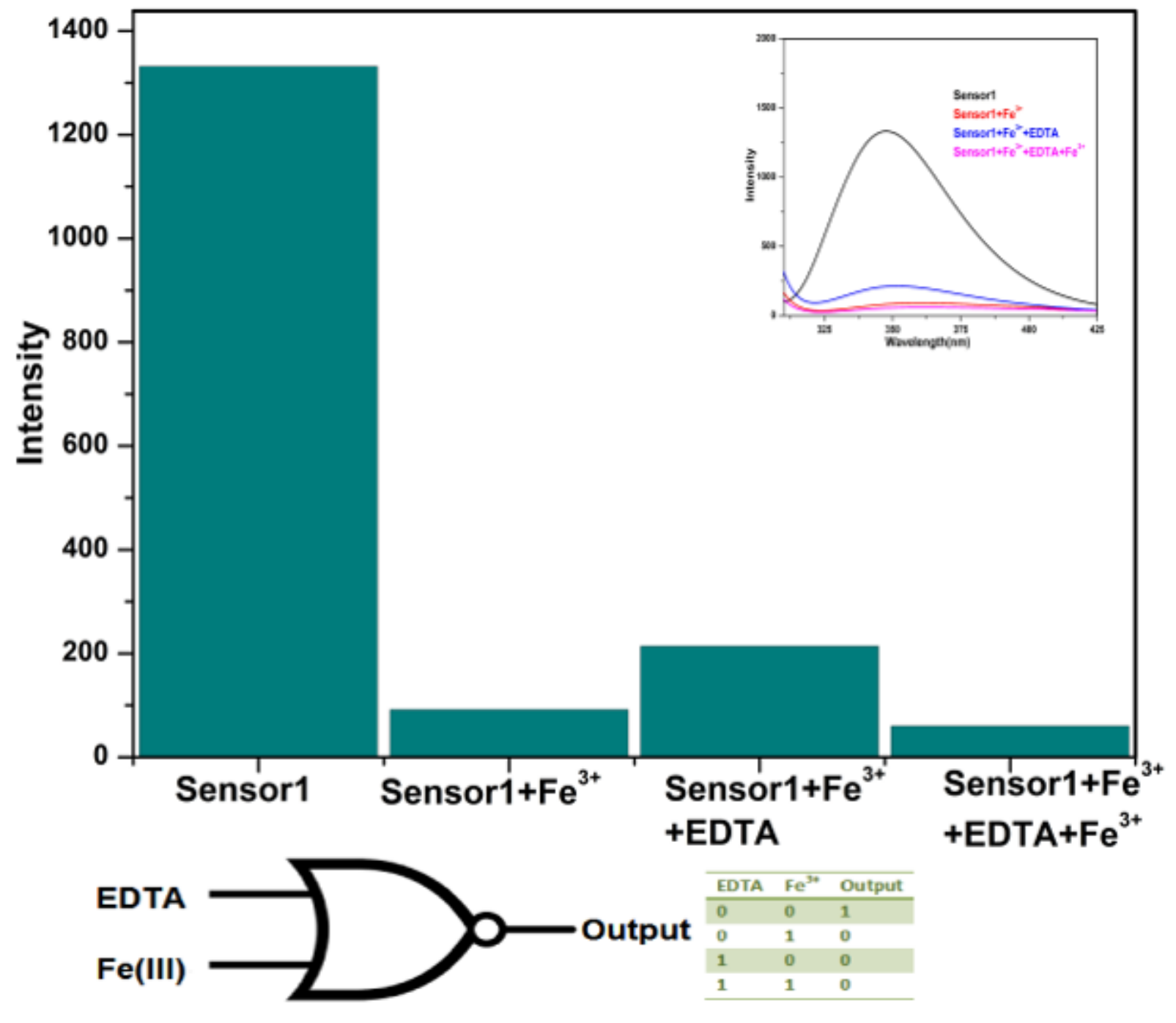

Figure 6

Bar graph showing quenching and restoration of intensity by addition of Fe3+ and EDTA respectively. (Inset)Emission spectra of sensor1. 
(a)
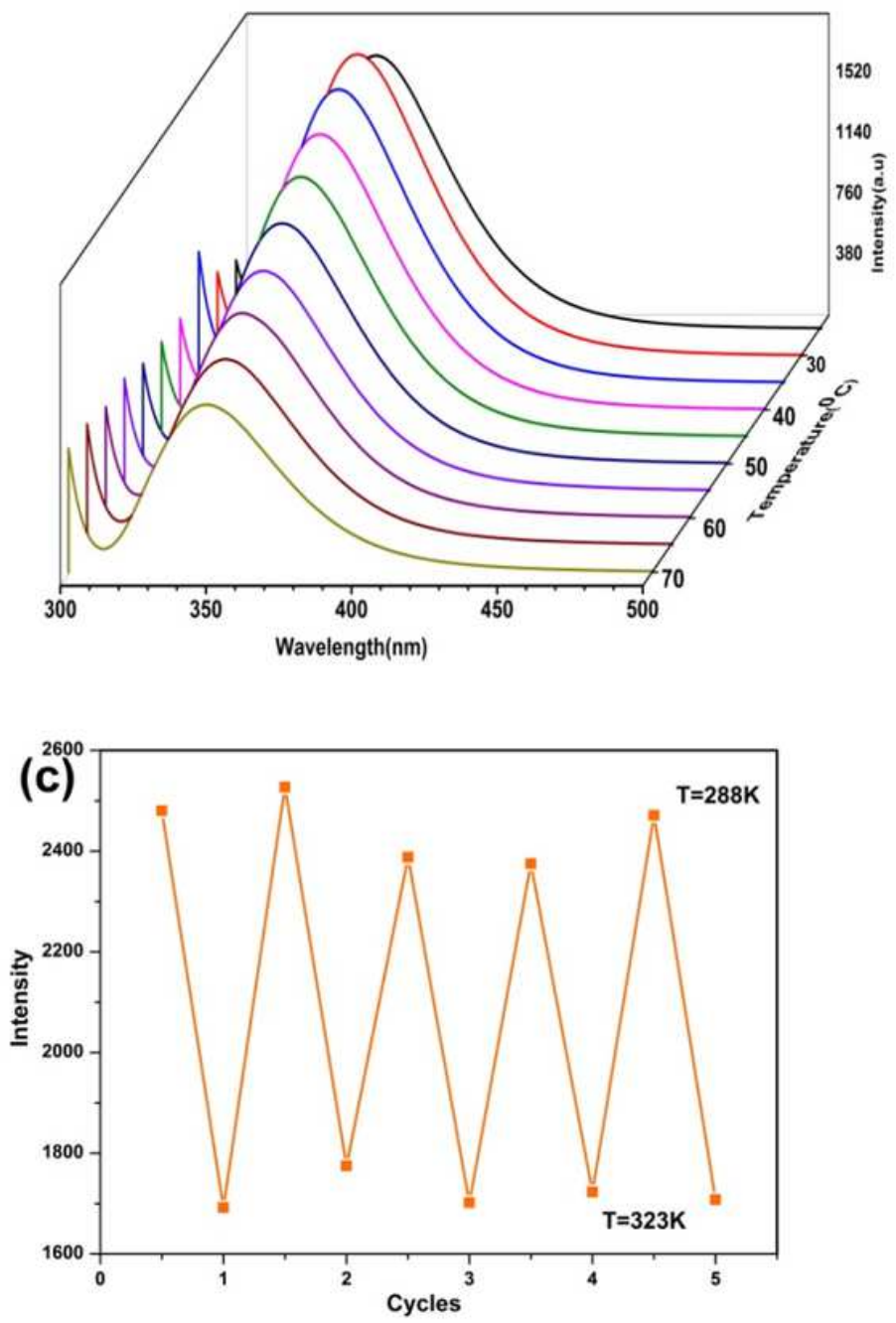
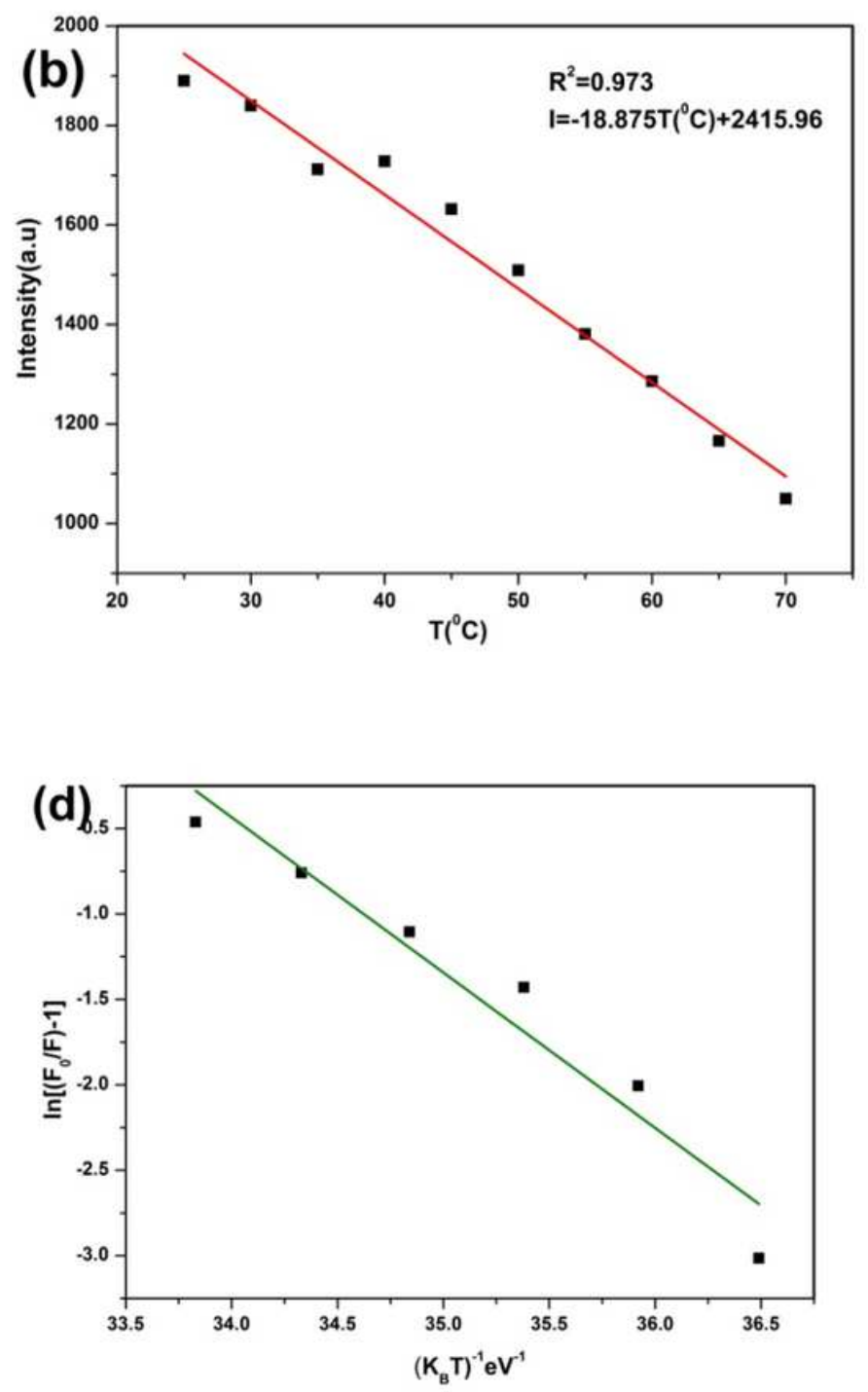

Figure 7

(a) Decreased fluorescence intensities with increasing temperatures of sensor1. (b) Graph of intensity Vs temperature in ${ }^{\circ} \mathrm{C}$ of sensor1. (c) Graph showing reversibility of sensor1 measured at $288 \mathrm{~K}$ and $323 \mathrm{~K}$ (d) Graph of In (F0/F-1) Vs 1/KBT of sensor1 to calculate activation energy. 


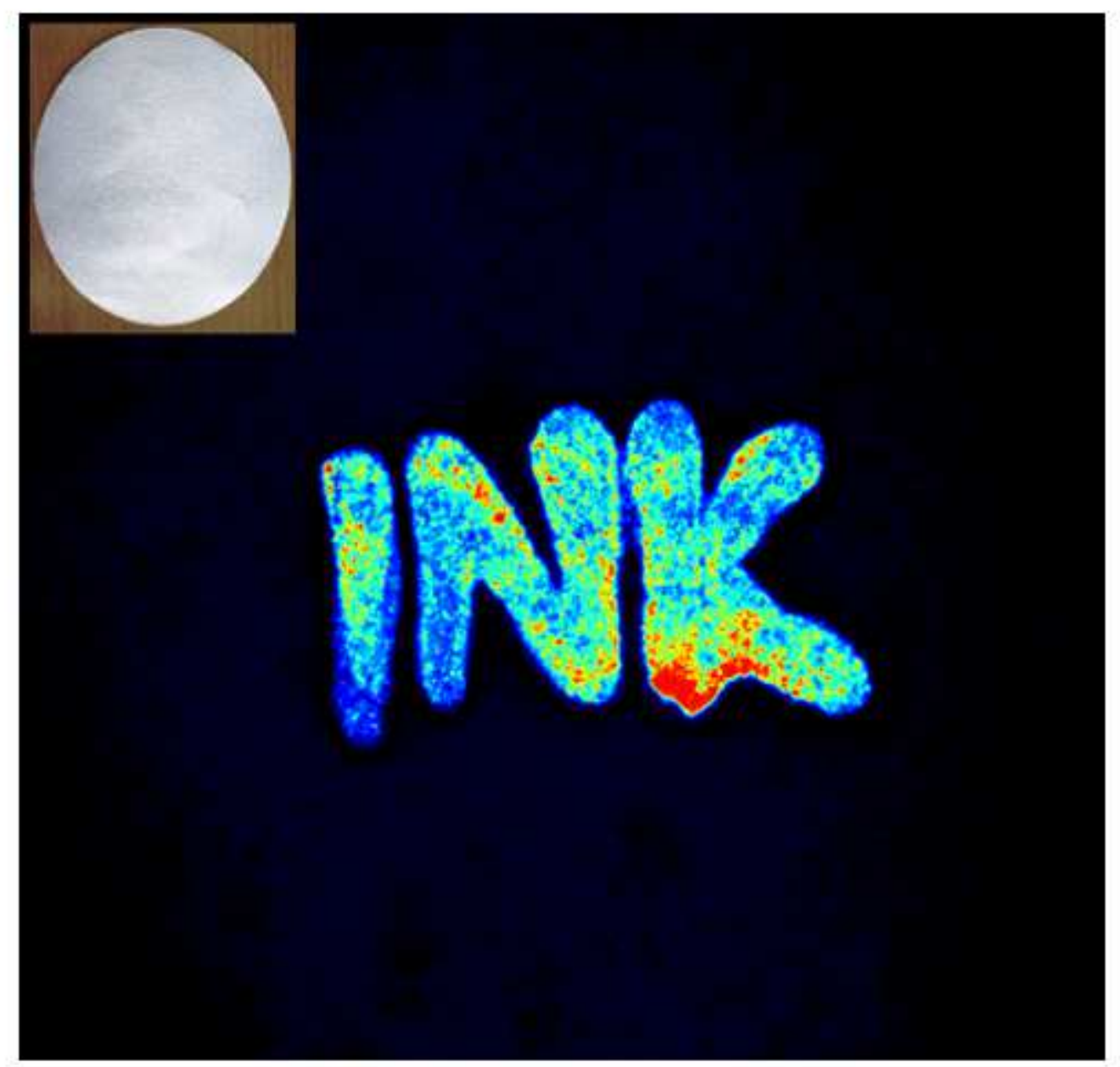

Figure 8

sensor1 as fluorescent ink. Excited at 350nm. (Inset) Image taken in a day light.

\section{Supplementary Files}

This is a list of supplementary files associated with this preprint. Click to download.

- GraphicalabstractJF.pdf 